\title{
NO-induced migraine attack: strong increase in plasma calcitonin gene-related peptide (CGRP) concentration and negative correlation with platelet serotonin release
}

\author{
Gabriella Juhasz ${ }^{\mathrm{a}}$, Terezia Zsombok ${ }^{\mathrm{a}}$, Edit A. Modos ${ }^{\mathrm{a}}$, Sarolta Olajos ${ }^{\mathrm{b}}$, Balazs Jakab ${ }^{\mathrm{c}}$, \\ Jozsef Nemeth ${ }^{\mathrm{c}}$, Janos Szolcsanyi ${ }^{\mathrm{c}}$, Jozsef Vitrai ${ }^{\mathrm{d}}$, Gyorgy Bagdy ${ }^{\mathrm{a}, *}$ \\ ${ }^{a}$ Laboratory of Neurochemistry and Experimental Medicine, Department of Vascular Neurology, Faculty of Medicine, \\ Semmelweis University, National Institute of Psychiatry and Neurology, Huvosvolgyi ut 116, Budapest H-1021, Hungary \\ ${ }^{\mathrm{b}}$ Laboratory of Pharmacokinetics, Department of Vascular Neurology, Faculty of Medicine, Semmelweis University, \\ National Institute of Psychiatry and Neurology, Budapest, Hungary \\ ${ }^{\mathrm{c}}$ Neuropharmacology Research Group of the Hungarian Academy of Sciences, Department of Pharmacology and Pharmacotherapy, \\ University of Pecs, Pecs, Hungary \\ ${ }^{\mathrm{d}}$ Johan Bela National Center of Epidemiology, Budapest, Hungary
}

Received 31 January 2003; received in revised form 27 August 2003; accepted 16 September 2003

\begin{abstract}
The aim of the present study was to investigate changes in the plasma calcitonin gene-related peptide (CGRP) concentration and platelet serotonin (5-hydroxytriptamine, 5-HT) content during the immediate headache and the delayed genuine migraine attack provoked by nitroglycerin. Fifteen female migraineurs (without aura) and eight controls participated in the study. Sublingual nitroglycerin ( $0.5 \mathrm{mg}$ ) was administered. Blood was collected from the antecubital vein four times: $60 \mathrm{~min}$ before and after the nitroglycerin application, and 60 and 120 min after the beginning of the migraine attack (mean 344 and 404 min; 12 subjects). In those subjects who had no migraine attack (11 subjects) a similar time schedule was used. Plasma CGRP concentration increased significantly $(P<0.01)$ during the migraine attack and returned to baseline after the cessation of the migraine. In addition, both change and peak, showed significant positive correlations with migraine headache intensity $(P<0.001)$. However, plasma CGRP concentrations failed to change during immediate headache and in the subjects with no migraine attack. Basal CGRP concentration was significantly higher and platelet 5-HT content tended to be lower in subjects who experienced a migraine attack. Platelet serotonin content decreased significantly $(P<0.01)$ after nitroglycerin in subjects with no migraine attack but no consistent change was observed in patients with migraine attack. In conclusion, the fact that plasma CGRP concentration correlates with the timing and severity of a migraine headache suggests a direct relationship between CGRP and migraine. In contrast, serotonin release from platelets does not provoke migraine, it may even counteract the headache and the concomitant CGRP release in this model.
\end{abstract}

(C) 2003 International Association for the Study of Pain. Published by Elsevier B.V. All rights reserved.

Keywords: Headache; Migraine; Nitroglycerin; Nitric oxide; Calcitonin gene-related peptide; Platelet serotonin

\section{Introduction}

Nitroglycerin is an organic nitrate ester that has vasodilatory properties. The direct formation of nitric oxide (NO) from organic nitrates has been shown in several

Abbreviations: NO, nitric oxide; NOS, nitric oxide synthase; cGMP, cyclic guanylate monophosphate; SP, substance P; CGRP, calcitonin generelated peptide; 5-HT, 5-hydroxytriptamine; ANOVA, analysis of variance.

* Corresponding author. Tel.: + 36-1-3915407; fax: + 36-1-3915305.

E-mail address: bag13638@mail.iif.hu (G. Bagdy). tissues (Tassorelli and Joseph, 1996). Furthermore, endogenous NO is synthesized by various isoforms of nitric oxide synthase (NOS) (Ohkuma and Katsura, 2001), which are encoded by distinct genes (Griffiths et al., 1997). NO is an important mediator of vasodilatation in intra- and extracranial blood vessels, and is also an algogenic substance (Iversen, 1995). This small and almost ubiquitous messenger molecule does not interact with specific receptors, but diffuses freely across membranes (Ohkuma and Katsura, 2001). NO diffuses into vascular smooth 
muscle where it activates soluble guanylate cyclase with the formation of cyclic guanylate monophosphate (cGMP), which in turn, relaxes the muscles and dilates the blood vessels (Zicari et al., 2001). Furthermore, NO modulates the neuronal release of neurotransmitters in both in vitro and in vivo conditions (Prast and Philippu, 2001).

Previous studies have shown that migraineurs experience a delayed migraine-like headache in association with nitroglycerin administration more often than non-migraineurs (Olesen et al., 1993). It appears that NO initiates a slow pathological reaction that, eventually, leads to a headache attack; it is also seen that migraineurs are supersensitive to both exogenous and endogenous NO (Olesen et al., 1994). Artificially increased concentrations of NO are able to increase NO synthase availability in nociceptive trigeminal neurons (Knyihar-Csillik and Vecsei, 1999; Pardutz et al., 2000). At the level of the trigeminal system, neuronal NOS appears to coordinate NO production to activate calcitonin gene-related peptide (CGRP) release from trigeminal fibres which in turn triggers vasodilatation. At the level of the blood vessels themselves, CGRP appears to activate endothelial NO synthase to cause further NO production and thus relaxation of blood vessel smooth muscle with attendant dilation (Akerman et al., 2002; Goadsby et al., 1990; Lassen et al., 2002; Sarchielli et al., 2000). However, it is not yet clearly understood why migraine sufferers respond more severely to NO than the controls.

The aim of the present study was to evaluate how plasma CGRP concentration and platelet serotonin content change in peripheral blood circulation during a reproducible and accurate human migraine model such as nitroglycerininduced headache.

\section{Materials and methods}

\subsection{Study subjects}

Fifteen unrelated migraine patients without aura (migraineurs; mean age: $41.9 \pm 2.3$ years) and eight unrelated healthy controls (mean age: $38.5 \pm 4.4$ years) were included in the study. All individuals were females. A detailed medical history was taken from each subject, and they underwent complete physical, neurological and psychological examinations and laboratory studies before participating in the project. Control subjects have rare (less than 1/year) and mild headaches only. Patients using frequent analgesic medications (corresponding to more than $2 \mathrm{~g}$ of aspirin/day) were excluded from the study. The diagnoses for headache were made according to the criteria of the International Headache Society (IHS, 1988). None of the subjects were suffering from psychiatric disorders of any kind according to the criteria of the DSM-IV (DSM-IV, 1994). At the time of the study, all participants were medication-free (including oral contraceptives) and were not following any particular diet. All subjects were studied during the mid follicular phase (between days 5 and 10 of the menstrual cycle).

We used an open label case control design. The study protocol was approved by the local ethics committee for experimentation on humans and every subject gave written informed consent before participating in the research.

\subsection{Procedure}

The subjects arrived at the laboratory at 6.30 a.m. and were observed until 5.00 p.m. Headache intensity and characteristics were measured at baseline (7.00 a.m.) and every $20 \mathrm{~min}$ thereafter for the duration of the observation period. Headache intensity was scored on a verbal scale that measured from 0 to 10 : 1 , a very mild headache including pre-pain (feeling of pressure); 5, a headache of medium severity; and 10, a very severe headache. The subjects were asked after the standardized procedure about pain localization and quality, and side effects were recorded.

Sublingual administration of $0.5 \mathrm{mg}$ nitroglycerin was used as a test at 8.00 a.m.

Venous blood was drawn from an antecubital vein four times during the test day using the Vacutainer ${ }^{\circledR}$ system. Baseline blood samples were collected at 7.00 a.m. after a $30 \mathrm{~min}$ rest period. At 8.00 a.m. subjects received a $0.5 \mathrm{mg}$ dose of sublingual nitroglycerin. The second blood sample was taken after sublingual nitroglycerin at 9.00 a.m. The next two blood samples were taken 60 and $120 \mathrm{~min}$ after the beginning of the migraine attack (mean 344 and 404 min after nitroglycerin). In subjects with no migraine attack, similar time schedules were used based on our preliminary data (third blood sample $5 \mathrm{~h}$ and fourth blood sample $6 \mathrm{~h}$ after nitroglycerin).

Subjects were free to withdraw at any time during the study and treatment was offered if needed. None of the subjects whose data are presented here received any drug treatment before the last blood sampling.

\subsection{Determination of plasma CGRP level}

\subsubsection{Drugs and chemicals}

Rat Tyr- $\alpha$-CGRP (23-37) (Bachem, Budendorf, Switzerland), EDTA, $\mathrm{Na}_{2} \mathrm{HPO}_{4}, \mathrm{NaH}_{2} \mathrm{PO}_{4}$ (Reanal, Budapest, Hungary), Aprotinin (Richter, Budapest, Hungary), $30 \%$ bovine albumin solution (Sigma, St. Louis, USA) were used. ${ }^{125}$ I-labelled Tyr- $\alpha$-CGRP (23-37) was prepared in our laboratory (Nemeth et al., 2002). CGRP antiserum was provided by Dr T. Gorcs, Semmelweis Medical University, Budapest.

For the determination of plasma CGRP immunoreactivity, venous blood samples ( $3 \mathrm{ml} /$ patient) were taken into ice-cold tubes containing EDTA $(7.5 \% \quad 0.072 \mathrm{ml} / 3 \mathrm{ml}$ blood) and aprotinin (2700 KIU/3 ml blood). Following centrifugation $\left(3000 \mathrm{rpm}\right.$ for $15 \mathrm{~min}$ at $4{ }^{\circ} \mathrm{C}$ ) the plasma was 
aspirated and stored at $-80{ }^{\circ} \mathrm{C}$ until plasma CGRP determination. Plasma CGRP concentrations were measured by means of a specific and sensitive radioimmunoassay (RIA) method (Nemeth et al., 1998). Plasma CGRP concentrations were measured by examiners who were not familiar with the subjects participating in the study.

\subsection{Determination of platelet serotonin content}

The 5-hydroxytriptamine (5-HT) concentration was determined from platelet-rich-plasma by high-pressure liquid chromatography (HPLC) coupled with electrochemical detection as described earlier (Guicheney, 1988; Kantor et al., 2001). Blood from the cubital vein was obtained in tubes containing EDTA. Platelet-rich plasma was routinely prepared by centrifugation and platelets were counted by phase contrast microscopy. Platelet lyses was induced by the addition of perchloric acid and methanol. The supernatant was kept at $-80{ }^{\circ} \mathrm{C}$ until the assay was performed. The 5-HT concentration was measured by HPLC that included an LKB-Pharmacia 2248-010 pump, a 5 C-18 Nucleosil RP column and an electrochemical detector. Results were calculated from standard and sample peak height ratios. Serotonin content was expressed in $\mathrm{ng} / 10^{8}$ platelets. Platelet 5-HT concentrations were measured by examiners who were not familiar with the subjects participating in the study.

\subsection{Statistical analysis}

One-way, two-way and repeated measure analyses of variance (ANOVA) with post-hoc comparisons (NewmanKeuls) were applied for testing the statistical differences between the means of CGRP and 5-HT with regard to diagnoses and time. Friedman's non-parametric ANOVA was used to test changes in headache scores over time. Statistical differences in headache scores among groups were compared using the Mann-Whitney $U$ test. Significance levels were adjusted for multiple comparisons using a Bonferroni correction. The $\chi^{2}$ test was applied for statistical analysis to search for any differences between the ratios of patients who experienced headache in the different groups. Correlation for headache scores versus 5-HT or CGRP concentration was quantified using the Spearman rank correlation coefficient. Correlation for basal CGRP concentrations versus peak CGRP changes was done with Pearson product moment correlation test. All procedures were carried out using Statistica 5 for Windows (StatSoft, 1997). Results were presented as the mean \pm standard error of mean; $P<0.05$ was considered significantly different.

\section{Results}

All data were analyzed in two separate ways, primarily according to the development of migraine attack (migraine

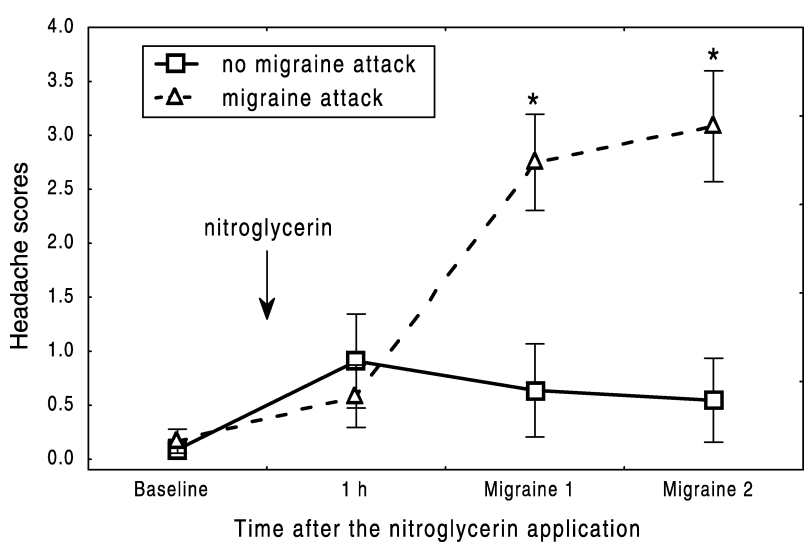

Fig. 1. Effects of nitroglycerin $(0.5 \mathrm{mg}$ sublingual) on headache scores $(0-$ 10 verbal scale $)$ in subjects with migraine attack $(n=12)$ and subjects with no migraine attack $(n=11)$. Values are mean \pm SEM headache scores. Baseline blood samples were collected at 7.00 a.m. A secondary blood sample was taken $1 \mathrm{~h}$ after sublingual application of nitroglycerin, at 9.00 a.m. The next two blood samples were taken 60 (migraine 1) and $120 \mathrm{~min}$ (migraine 2) after the beginning of the migraine attack (mean 344 and 404 min after nitroglycerin). In subjects with no migraine attack, similar time schedules were used based on our preliminary data (migraine $1: 5 \mathrm{~h}$ and migraine $2: 6 \mathrm{~h}$ after nitroglycerin, respectively). ${ }^{*}$ Significant changes after sublingual nitroglycerin compared to baseline, $P<0.01$.

attack versus no migraine attack, see Figs. 1-4), and secondly according to the clinical diagnosis (migraineurs versus controls, see Tables 1-3).

\subsection{Headaches}

Two out of the eight control subjects and 10 out of the 15 migraineurs developed an immediate headache (mean

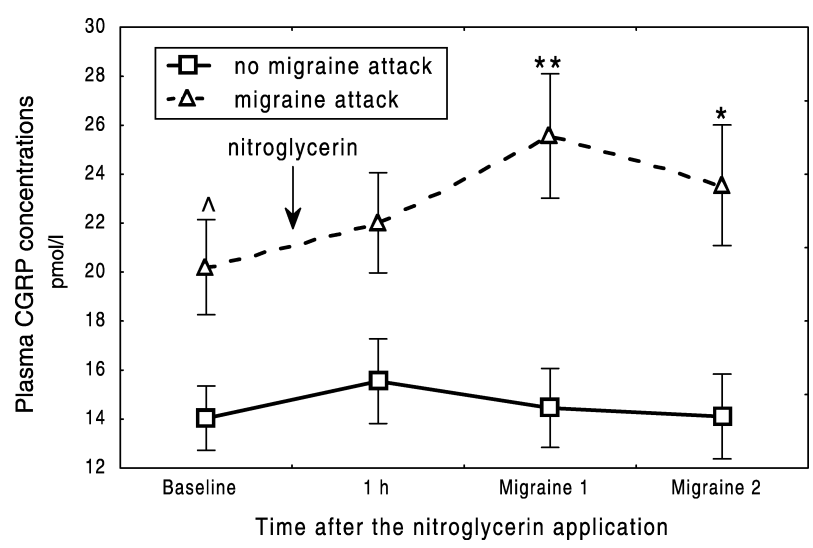

Fig. 2. Effects of nitroglycerin ( $0.5 \mathrm{mg}$ sublingual) on plasma CGRP concentrations in subjects with migraine attack $(n=12)$ and subjects with no migraine attack $(n=11)$. Values are mean \pm SEM CGRP concentrations. Baseline blood samples were collected at 7.00 a.m. A secondary blood sample was taken $1 \mathrm{~h}$ after sublingual application of nitroglycerin, at 9.00 a.m. The next two blood samples were taken 60 (migraine 1) and 120 min (migraine 2) after the beginning of the migraine attack (mean 344 and 404 min after nitroglycerin). In subjects with no migraine attack, similar time schedules were used based on our preliminary data (migraine 1: $5 \mathrm{~h}$ and migraine 2: $6 \mathrm{~h}$ after nitroglycerin, respectively). ${ }^{\wedge}$ Significant difference in baseline values, $P<0.05$. Significant changes after sublingual nitroglycerin compared to baseline, ${ }^{*} P<0.05$; ${ }^{*} P<0.001$. 

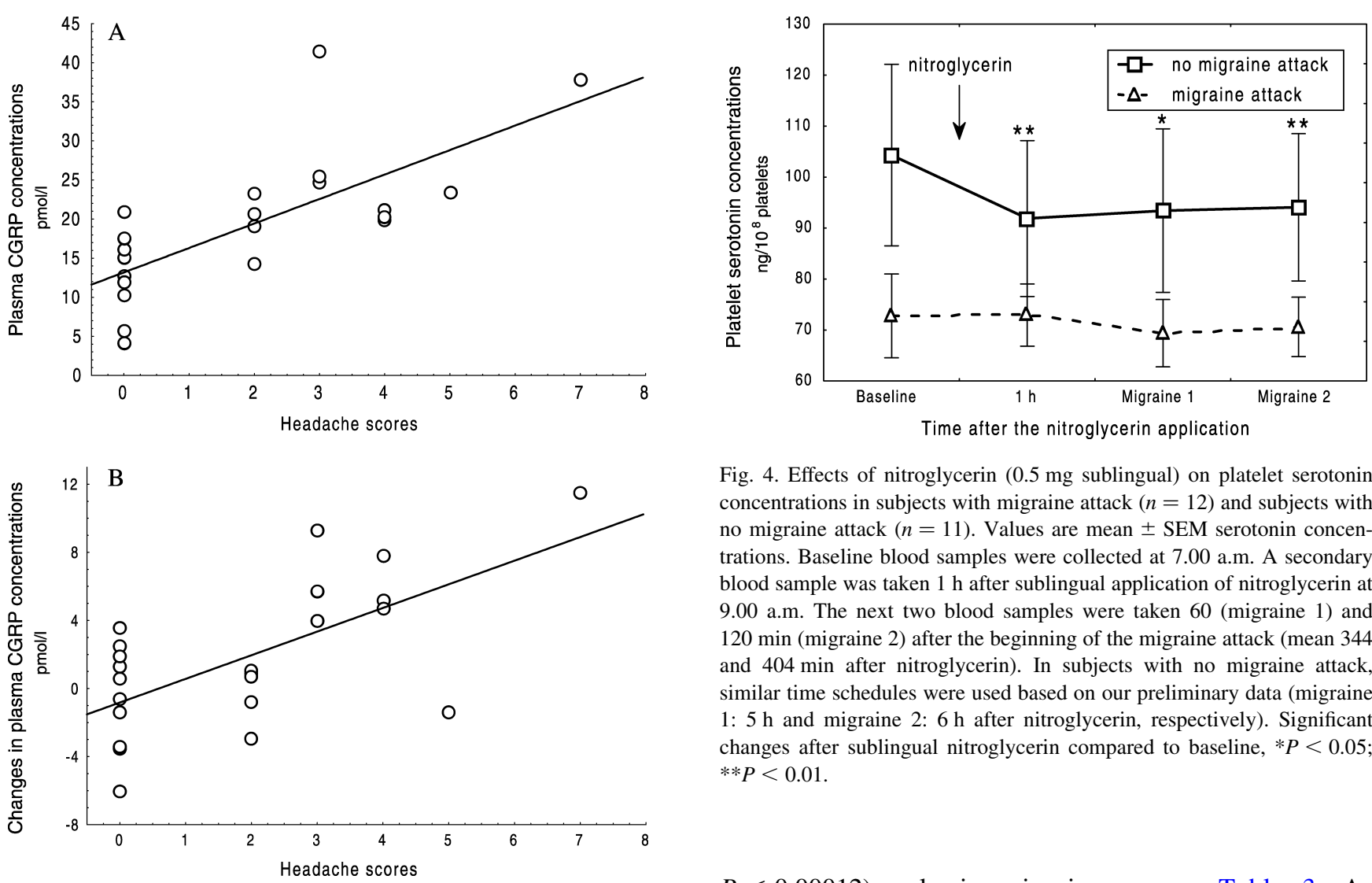

Fig. 4. Effects of nitroglycerin ( $0.5 \mathrm{mg}$ sublingual) on platelet serotonin concentrations in subjects with migraine attack $(n=12)$ and subjects with no migraine attack $(n=11)$. Values are mean \pm SEM serotonin concentrations. Baseline blood samples were collected at 7.00 a.m. A secondary blood sample was taken $1 \mathrm{~h}$ after sublingual application of nitroglycerin at 9.00 a.m. The next two blood samples were taken 60 (migraine 1) and 120 min (migraine 2) after the beginning of the migraine attack (mean 344 and 404 min after nitroglycerin). In subjects with no migraine attack, similar time schedules were used based on our preliminary data (migraine 1: $5 \mathrm{~h}$ and migraine 2: $6 \mathrm{~h}$ after nitroglycerin, respectively). Significant changes after sublingual nitroglycerin compared to baseline, $* P<0.05$; $* * P<0.01$.

$P<0.00012$ ) only in migraineurs, see Table 3. As expected, migraine headache developed more frequently among migraineurs ( $\chi^{2}$ test: $\left.\chi^{2}=3.63, \mathrm{df}=1, P=0.057\right)$ and the severity of the attacks was also higher. For further information about the headache characteristics of migraine attacks and accompanying symptoms, see Table 2 .

\subsection{Basal neurochemical measures}

latency: $12.5 \pm 4.7 \mathrm{~min}$ ) after the nitroglycerin test (sublingual $0.5 \mathrm{mg}$ ), see Tables 1 and 2 . This headache did not fulfill the IHS criteria for migraine without aura (median headache score 1 , range $0-4$ ), lasting only a few minutes (mean $31.7 \pm 5.2 \mathrm{~min}$ ), and disappearing spontaneously. Typical migraine attacks that fulfilled the IHS criteria for migraine without aura, developed in two of the control subjects and 10 of the migraineurs (median headache score 3.5 , range 2-7). Characteristics and accompanying symptoms of usual migraine headache and migraine-type headache after nitroglycerin are summarized in Table 2. Out of the 12 subjects with migraine attack, only seven had immediate headache, see Tables 1 and 2. The mean latency for the migraine attacks was $284.2 \pm 90.3 \mathrm{~min}$.

Immediate headache and migraine headache scores in subjects with no migraine attack and in subjects with migraine attack are shown in Fig. 1. There was no significant difference in immediate headache scores between the two groups (Mann-Whitney $U$ test: $U=61.0, P=0.76)$.

There was a statistically significant increase in headache scores (Friedman ANOVA: $\chi^{2}=20.7, N=15$, df $=3$,

\subsubsection{According to the development of headache}

Basal CGRP concentrations were significantly higher (one-way ANOVA: $F=6.65$, df $=1,21, P=0.018$ ) in those subjects who developed migraine attack $(20.2 \pm 1.9 \mathrm{pmol} / \mathrm{l})$ when compared to the subjects with no migraine attack $(14.0 \pm 1.3 \mathrm{pmol} / \mathrm{l})$. In contrast, basal CGRP concentration was not significantly different in subjects who developed immediate headache

Table 1

Immediate headache and migraine attack frequency in the study population

\begin{tabular}{|c|c|c|c|c|c|}
\hline \multirow[t]{2}{*}{$\begin{array}{l}\text { Diagnosis } \\
\text { (number) }\end{array}$} & \multicolumn{2}{|c|}{$\begin{array}{l}\text { Immediate } \\
\text { headache }\end{array}$} & \multicolumn{2}{|c|}{$\begin{array}{l}\text { Migraine } \\
\text { attack }\end{array}$} & \multirow[t]{2}{*}{$\begin{array}{l}\text { Both types } \\
\text { of headache }\end{array}$} \\
\hline & Yes & No & Yes & No & \\
\hline Migraineurs (15) & 10 & 5 & 10 & 5 & 6 \\
\hline Controls (8) & 2 & 6 & 2 & 6 & 1 \\
\hline Totals & 12 & 11 & 12 & 11 & 7 \\
\hline
\end{tabular}


Table 2

(a) Clinical characteristics of participants' usual headache (control subjects have rare-less than 1/year-and mild headaches only). (b) Presence of immediate, non-migraine type headache within the first hour and clinical characteristics of maximal headache scores from 1 to $12 \mathrm{~h}$ after the nitroglycerin test

\begin{tabular}{|c|c|c|c|c|c|c|c|c|c|c|c|}
\hline \multirow[t]{2}{*}{ Subject } & \multirow{2}{*}{\multicolumn{2}{|c|}{$\begin{array}{l}\text { Immediate } \\
\text { headache }\end{array}$}} & \multicolumn{5}{|c|}{ Headache characteristic of usual and NO-induced late headache } & \multicolumn{4}{|c|}{ Accompanying symptoms } \\
\hline & & & Time & Localization & Intensity & Quality & Aggravate & Nausea & Photo & Phono & IHS \\
\hline \multirow[t]{2}{*}{1} & $\mathrm{a}$ & & & Left & Mod/sev & Puls & Yes & Yes & Yes & Yes & M \\
\hline & $\mathrm{b}$ & No & 5 & Left & 3 & Puls & Yes & No & Yes & No & Yes \\
\hline \multirow[t]{2}{*}{2} & $\mathrm{a}$ & & & Right/left & Severe & Puls & Yes & Yes & Yes & Yes & M \\
\hline & $\mathrm{b}$ & Yes & 1 & Bilat & 4 & Cons & No & No & No & No & No \\
\hline 3 & $\mathrm{~b}$ & Yes & 6 & Bilat & 5 & Puls & Yes & Yes & No & Yes & Yes \\
\hline \multirow[t]{2}{*}{4} & $\mathrm{a}$ & & & Left & Severe & Puls & Yes & Yes & Yes & Yes & M \\
\hline & $\mathrm{b}$ & No & 7 & Bilat & 7 & Puls & Yes & Yes & Yes & Yes & Yes \\
\hline \multirow[t]{2}{*}{5} & $\mathrm{a}$ & & & Bilat & Mod/sev & Puls & Yes & No & Yes & Yes & $\mathrm{M}$ \\
\hline & $\mathrm{b}$ & Yes & 6 & Right/bilat & 6 & Puls & Yes & No & Yes & No & Yes \\
\hline \multirow[t]{2}{*}{6} & $\mathrm{a}$ & & & Right & Severe & Puls & Yes & Yes & Yes & No & M \\
\hline & $\mathrm{b}$ & Yes & 7 & Right & 6 & Puls & Yes & Yes & Yes & Yes & Yes \\
\hline 7 & $\mathrm{~b}$ & No & & & 0 & & No & No & No & No & No \\
\hline \multirow[t]{2}{*}{8} & $\mathrm{a}$ & & & Left & Mod/sev & Puls & Yes & Yes & Yes & No & M \\
\hline & $\mathrm{b}$ & No & 6 & Left & 4 & Puls & Yes & Yes & Yes & No & Yes \\
\hline \multirow[t]{2}{*}{9} & $\mathrm{a}$ & & & Bilat & Mild & Cons & No & No & No & No & $\mathrm{CO}$ \\
\hline & $\mathrm{b}$ & No & & & 0 & & No & No & No & No & No \\
\hline \multirow[t]{2}{*}{10} & $\mathrm{a}$ & & & Right/left & Severe & Puls & Yes & Yes & Yes & Yes & $\mathrm{M}$ \\
\hline & $\mathrm{b}$ & Yes & 5 & Left & 3 & Puls & Yes & Yes & Yes & Yes & Yes \\
\hline \multirow[t]{2}{*}{$11 *$} & $\mathrm{a}$ & & & Bilat & Mild & Cons & No & No & No & No & $\mathrm{CO}$ \\
\hline & $\mathrm{b}$ & Yes & 5 & Left & 2 & Puls & Yes & No & Yes & Yes & Yes \\
\hline \multirow[t]{2}{*}{12} & $\mathrm{a}$ & & & Right & Severe & Puls & Yes & Yes & Yes & Yes & $\mathrm{M}$ \\
\hline & $\mathrm{b}$ & Yes & 5 & Right & 3 & Puls & Yes & Yes & Yes & Yes & Yes \\
\hline \multirow[t]{2}{*}{13} & $\mathrm{a}$ & & & Bilat & Mild & Cons & No & No & No & No & $\mathrm{CO}$ \\
\hline & $\mathrm{b}$ & Yes & 1 & Bilat & 2 & Cons & No & No & No & No & No \\
\hline \multirow[t]{2}{*}{14} & $\mathrm{a}$ & & & Bilat & Mild & Cons & No & No & No & No & $\mathrm{CO}$ \\
\hline & $\mathrm{b}$ & No & & & 0 & & No & No & No & No & No \\
\hline 15 & $\mathrm{a}$ & & & Bilat & Mild & Cons & No & No & No & No & $\mathrm{CO}$ \\
\hline & $\mathrm{b}$ & No & 7 & Right & 2 & Puls & Yes & No & Yes & Yes & Yes \\
\hline 17 & $\mathrm{a}$ & & & Right & Mod/sev & Puls & Yes & Yes & Yes & No & M \\
\hline & $\mathrm{b}$ & Yes & 1 & Bilat & 3 & Cons & No & No & No & No & No \\
\hline 18 & $\mathrm{a}$ & & & Bilat & Mild & Cons & No & No & No & No & $\mathrm{CO}$ \\
\hline & $\mathrm{b}$ & No & & & 0 & & No & No & No & No & No \\
\hline 19 & $\mathrm{a}$ & & & Right & Mod/sev & Puls & Yes & Yes & Yes & No & M \\
\hline & $\mathrm{b}$ & Yes & 8 & Bilat & 5 & Puls & Yes & Yes & Yes & No & Yes \\
\hline 20 & $\mathrm{a}$ & & & Bilat & $\mathrm{Mod} / \mathrm{sev}$ & Puls & Yes & Yes & Yes & Yes & $\mathrm{M}$ \\
\hline & $\mathrm{b}$ & Yes & 1 & Bilat & 1 & Cons & No & No & No & No & No \\
\hline $21 * *$ & $\mathrm{a}$ & & & Bilat & Mild & Cons & No & No & No & No & $\mathrm{CO}$ \\
\hline & $\mathrm{b}$ & No & 5 & Bilat & 2 & Puls & Yes & Yes & Yes & No & Yes \\
\hline 22 & $\mathrm{a}$ & & & Left & Severe & Puls & Yes & Yes & No & No & $\mathrm{M}$ \\
\hline & $\mathrm{b}$ & Yes & & & 0 & & No & Yes & No & No & No \\
\hline 23 & $\mathrm{a}$ & & & Bilat & Mild & Cons & No & No & No & No & $\mathrm{CO}$ \\
\hline & $\mathrm{b}$ & No & & & 0 & & No & No & No & No & No \\
\hline
\end{tabular}

Immediate headache, atypical headache (not fulfilling the IHS criteria for migraine without aura) within the first hour; time, time to peak headache after the sublingual application of nitroglycerin; localization, bilateral or right/left hemisphere; intensity, intensity of headache scored on a scale from 0 to 10 ; quality, constant or pulsating; aggravate, intensity of headache aggravated by physical activity; photo, photophobia; phono, phonophobia; IHS, yes, M, fulfilling the IHS criteria for migraine without aura; IHS, no, CO, not fulfilling the IHS criteria for migraine without aura. *One bilateral, pulsating headache with vomiting several years ago. **Rare headaches after sleep deprivation with intensity of headache aggravated by physical activity.

$(18.8 \pm 1.9 \mathrm{pmol} / \mathrm{l})$ when compared to those without immediate headache $(15.6 \pm 1.8$ pmol/l), see Fig. 2.

Basal platelet serotonin content was somewhat lower (one-way ANOVA: $F=2.74$, $\mathrm{df}=1,21, P=0.11$ ) in subjects with typical migraine attack $\left(72.8 \pm 8.2 \mathrm{ng} / 10^{8}\right.$ pts) when compared to the subjects with no migraine attack $\left(104.3 \pm 17.8 \mathrm{ng} / 10^{8} \mathrm{pts}\right)$. Basal platelet serotonin content was not significantly different (one-way ANOVA: 
Table 3

Headache scores, plasma CGRP concentrations and platelet serotonin concentrations (mean \pm SEM) in controls and migraineurs during the nitroglycerin test

\begin{tabular}{|c|c|c|c|c|c|c|c|c|}
\hline \multirow[t]{2}{*}{ Time } & \multicolumn{4}{|c|}{ Controls (mean \pm SEM) } & \multicolumn{4}{|c|}{ Migraineurs (mean \pm SEM) } \\
\hline & $\mathrm{B}$ & 1 & 2 & 3 & $\mathrm{~B}$ & 1 & 2 & 3 \\
\hline Headache scores $(1-10)$ & $0.0 \pm 0.0$ & $0.25 \pm 0.25$ & $0.5 \pm 0.33$ & $0.5 \pm 0.33$ & $0.2 \pm 0.10$ & $1.0 \pm 0.35$ & $2.4 \pm 0.48^{* *}$ & $2.6 \pm 0.53^{* *}$ \\
\hline Plasma CGRP (pmol/l) & $15.1 \pm 2.0$ & $17.5 \pm 2.3$ & $16.5 \pm 2.3$ & $15.3 \pm 2.0$ & $18.4 \pm 1.7$ & $19.7 \pm 1.9$ & $22.2 \pm 2.6^{* *}$ & $21.0 \pm 2.4^{*}$ \\
\hline Platelet serotonin (ng/10 $0^{8}$ plts) & $111.1 \pm 23.3$ & $97.7 \pm 20.0^{*}$ & $101.0 \pm 21.3^{*}$ & $98.1 \pm 18.9 *$ & $75.5 \pm 7.7$ & $73.6 \pm 5.8$ & $70.2 \pm 5.9$ & $73.2 \pm 5.9$ \\
\hline
\end{tabular}

Baseline blood samples were collected at 7.00 a.m. A secondary blood sample was taken $1 \mathrm{~h}$ after the sublingual application of nitroglycerin, at 9.00 a.m. The next two blood samples (2 and 3) were taken 60 and $120 \mathrm{~min}$, respectively, after the beginning of a migraine attack (mean 344 and 404 min after nitroglycerin). In subjects with no migraine attack, similar time schedules were used based on our preliminary data (2: $5 \mathrm{~h}$ and $3: 6 \mathrm{~h}$ after nitroglycerin, respectively). Significant changes after sublingual nitroglycerin compared to baseline, $* P<0.05 ; * * P<0.01$.

$F=1.49, \mathrm{df}=1,21, P=0.24)$ in patients with immediate headache $\left(74.2 \pm 9.3 \mathrm{ng} / 10^{8} \mathrm{pts}\right)$ when compared to those without immediate headache $\left(102.7 \pm 17.4 \mathrm{ng} / 10^{8} \mathrm{pts}\right)$, see Fig. 4.

\subsubsection{According to the clinical diagnosis}

Basal CGRP concentrations were not significantly higher in migraineurs when compared to controls (M, $18.4 \pm 1.7 \mathrm{pmol} / \mathrm{l} ; \quad \mathrm{CO}, \quad 15.1 \pm 2.0 \mathrm{pmol} / \mathrm{l} ; \quad$ one-way ANOVA: $F=1.44$, df $=1,21, P=0.24$ ), see Table 3 .

Basal platelet serotonin content was somewhat lower (one-way ANOVA: $F=3.24$, df $=1,21, P=0.086$ ) in migraineurs $\left(75.5 \pm 7.7 \mathrm{ng} / 10^{8} \mathrm{pts}\right)$ when compared to the control subjects $\left(111.1 \pm 23.3 \mathrm{ng} / 10^{8} \mathrm{pts}\right)$, see Table 3 .

\subsection{Changes in neurochemical measures over time}

\subsubsection{According to the development of headache}

Nitroglycerin highly significantly increased the plasma CGRP concentration over time during the migraine attack (two-way ANOVA, no migraine attack vs. migraine attack subjects: $F=10.17$, df $=1,21, P=0.004$; group $\times$ time interaction: $F=3.58, \mathrm{df}=3,63, P=0.019$; Fig. 2). When separate ANOVA tests were run, significant increase (oneway ANOVA: $F=6.92$, df $=3,33, P=0.001$ ) in plasma CGRP concentrations were found in subjects with migraine attack but not in the subjects with no migraine attack (oneway ANOVA: $F=0.57$, df $=3,30, P=0.63$ ), see Fig. 2 .

Our results demonstrate that there is strong correlation between plasma CGRP concentrations and migraine headache scores (Spearman $R=0.70, P<0.001$ and Spearman $R=0.78, \quad P<0.0001$ in the 60th and 120th min after the beginning of migraine, respectively; Fig. 3). In addition, the changes in plasma CGRP content when compared to the basal values, showed significant correlation with migraine headache intensity (Spearman $R=0.55, P=0.006$ and Spearman $R=0.57, P=0.005$ in the 60th and 120th min after the beginning of migraine, respectively; Fig. 3). Furthermore, the peak changes of plasma CGRP concentrations when compared to basal values, showed significant correlation with basal CGRP concentration (Pearson $R=0.45, P=0.034$ ).
There were, however, no significant changes (one-way ANOVA: $F=1.79$, df $=1,11, P=0.21$ ) in plasma CGRP concentrations during the immediate headache, and the immediate headache scores did not correlate with the plasma CGRP concentration (Spearman $R=0.1$, $P=0.63$ ).

An early and long-lasting decrease in platelet serotonin content (one-way ANOVA: $F=4.85, \quad$ df $=3,30$, $P=0.007$ ) was found during the nitroglycerin test in those subjects who did not develop a migraine attack but not in the subjects who experienced a migraine attack (one-way ANOVA: $F=0.17$, df $=3,33, P=0.92$; Fig. 4). The decrease in platelet serotonin content was prolonged, and had not yet returned to the starting level at the time of the last blood sampling.

Furthermore, in subjects without immediate headache, a significant decrease in platelet serotonin content was observed $60 \mathrm{~min}$ after the nitroglycerin test (one-way ANOVA: $F=5.2, \mathrm{df}=1,10, P=0.046)$. There were no significant changes in platelet serotonin content in those subjects who developed an immediate headache (one-way ANOVA: $F=0.05$, df $=1,11, P=0.83)$. A significant negative correlation was observed between immediate headache scores and platelet serotonin content $60 \mathrm{~min}$ after nitroglycerin, when data of all subjects were included in the analysis (Spearman $R=-0.45, P=0.03$ ).

\subsubsection{According to the clinical diagnosis}

Generally, nitroglycerin showed a strong tendency to increase the plasma CGRP concentration over time (twoway ANOVA: $F=2.56$, df $=3,63, P=0.06$ ) but there was no significant difference between migraineurs and the control subjects (two-way ANOVA, migraineurs vs. control subjects: $F=1.77$, df $=1,21, P=0.2 ;$ group $\times$ time interaction: $F=1.63$, df $=3,63, P=0.19$ ). When separate ANOVA tests were run, a significant increase in plasma CGRP concentrations was found in migraineurs (one-way ANOVA: $F=4.24$, df $=3,42, P=0.01)$ but not in the control subjects (one-way ANOVA: $F=0.96$, df $=3,21$, $P=0.43$ ), see Table 3 .

Generally, nitroglycerin showed a tendency to decrease platelet serotonin concentration over time (two-way 
ANOVA: $F=2.07, \mathrm{df}=3,63, P=0.099)$ and there was a slight difference between migraineurs and control subjects (two-way ANOVA, migraineurs vs. control subjects: $F=2.97$, df $=1,21, P=0.11$; group $\times$ time interaction: $F=1.03$, df $=3,63, P=0.39$ ). When separate ANOVA tests were run, a significant decrease in platelet serotonin concentration was found in the control subjects (one-way ANOVA: $F=4.22$, df $=3,21, P=0.017$ ) but not in migraineurs (one-way ANOVA: $F=0.39$, df $=3,42$, $P=0.76)$, see Table 3 .

\subsubsection{Return of elevated CGRP concentration after the cessation of migraine attack}

Further blood samples were available from two patients after the migraine attack was eased using sumatriptan. In these patients, plasma CGRP concentration had decreased to the basal value (Headache: basal, 0 and 0; maximal, 3 and 3; after treatment, 0 and 1. CGRP: basal, 20.7 and $22.4 \mathrm{pmol} / \mathrm{l}$; at the time of maximal headache, 26.3 and $26.5 \mathrm{pmol} / \mathrm{l}$; after treatment, 19.8 and $20.2 \mathrm{pmol} / \mathrm{l}$ ) but no consistent changes were observed in platelet serotonin concentration (Platelet 5-HT: basal, 52.8 and $68.6 \mathrm{ng} / 10^{8} \mathrm{pts}$; at the time of maximal headache, 70.4 and $66.9 \mathrm{ng} / 10^{8} \mathrm{pts}$; after treatment, 72.2 and $49.3 \mathrm{ng} / 10^{8} \mathrm{pts}$ ).

\section{Discussion}

The aim of the present study was to evaluate the neurochemical changes after sublingual nitroglycerin application that may cause headache in migraineurs and sensitive healthy subjects. Even low doses of sublingual nitroglycerin are able to evoke a migraine attack in sensitive patients. High doses even cause a migraine-type headache in nonmigraineurs (Castellano et al., 1998; Christiansen et al., 2000; Iversen and Olesen, 1996). In our study, 10 out of the 15 migraineurs and two out of the eight controls developed a typical migraine attack during the nitroglycerin test. Previously all control subjects had only rare (less than $1 /$ year) and mild headaches. However, one out of the two controls who experienced migraine attack, had one bilateral, pulsating headache with vomiting several years ago and the other had rare headaches after sleep deprivation with the intensity of the headache aggravated by physical activity. These signs may predict sensitivity to NO and the development of the provoked headache in these subjects. The relatively variable effectiveness of sublingual nitroglycerin on headache, allowed us to compare induced headache to that of the neurochemical responses in those subjects who developed typical migraine attack and those did not. Furthermore, correlation between the intensity of the migraine attack and the neurochemical measures could be evaluated.

Trigeminal activation may lead to the release of CGRP into the cranial circulation, both in humans and in animal models (Goadsby et al., 1990; Knyihar-Csillik et al., 1997;
Lassen et al., 2002). Several primary headaches, such as migraine (Goadsby et al., 1990; Sarchielli et al., 2000), cluster (Fanciulacci et al., 1995; Edvinsson, 2000) and chronic paroxysmal hemicrania (Goadsby and Edvinsson, 1996) are associated with an increase in the CGRP level in the external and/or internal jugular vein during a pain attack. In addition, trigeminovascular activation has been shown to increase CGRP concentration in the jugular vein too. Similar, but less pronounced changes, were also seen in young migraineurs when CGRP was measured in the antecubital vein during the spontaneous migraine attacks (Gallai et al., 1995). Another study suggested that NO-induced immediate headache was not associated with the release of CGRP (Ashina et al., 2001).

Our results showed consistent, highly significant increases, in the peripheral plasma CGRP concentration during the nitroglycerin-induced migraine attack. These data support the hypothesis that migraine attacks are a result of trigeminovascular activation (Akerman et al., 2002). It seems that nitroglycerin triggers a cascade of events that subsequently lead to the release of CGRP in subjects who develop migraine attack. The mechanism of NO-induced pain is not clear, but animal studies suggest, that CGRP release does not require the production of cGMP, because guanilate cyclase inhibitor does not prevent NO-induced CGRP release (Garry et al., 2000).

In our study, plasma CGRP concentration failed to increase during the immediate headache. These data support the conclusion of previous studies (Ashina et al., 2001; Eltrop et al., 2000). This suggests that the initial headache may be caused by a direct action of the NO-cGMP pathway, that causes vasodilatation by vascular smooth muscle relaxation, independently of the CGRP release (Akerman et al., 2002).

It has been suggested that plasma levels of CGRP in the peripheral circulation are increased in adult migraineurs interictally (Ashina et al., 2000). It is remarkable that our results demonstrate that the higher basal plasma CGRP concentrations predispose subjects to develop migraine attack during the nitroglycerin test. In our study, increase in the CGRP concentrations correlates markedly with the migraine headache intensity. Furthermore, CGRP concentration returned to baseline after the migraine headache had ceased. These data suggest that blocking CGRP synthesis, release or receptors, may successfully prevent or alleviate migraine pain (Akerman et al., 2002; Buzzi and Moskowitz, 1992; Doods et al., 2000; Durham and Russo, 1999; Edvinsson, 2001; Goadsby and Edvinsson, 1993; Lassen et al., 2002). Several drugs, that in various ways antagonize the effects of CGRP, are presently known to be in preclinical and clinical trials, but no results are available in the public domain (Doods, 2001).

Thus, it is likely that nitroglycerin-induced migraine attack can only occur when particular pathophysiological conditions are present (Lassen et al., 2002). Evidence from experimental models of pain suggests that NO plays 
a crucial role in both central and peripheral sensitization (Knyihar-Csillik and Vecsei, 1999; Pardutz et al., 2000, 2002; Reuter et al., 2001). The long latency period, between nitroglycerin exposure and the fully developed migraine attack, indicates that the activation of $\mathrm{NO}-$ or steps in the NO-cGMP cascade_-initiates a rather slow ongoing process which results in a migraine attack in sensitive patients. It is possible that this process takes place in the trigeminovascular system, with the increased activity of neuronal NOS and the consequent activation of trigeminal fibres and nucleus (Akerman et al., 2002) or in the nociceptive modulation system (Tassorelli et al., 2002). Furthermore, increased NOS activity was demonstrated in patients with chronic daily headache and a previous history of migraine (Sarchielli et al., 2002), and in migraineurs (D'Amico et al., 2002; Sarchielli et al., 2000). This higher NOS activity may cause the higher basal CGRP level and, in addition, the correlation between the peak changes of plasma CGRP concentration compared to basal value supports this hypothesis.

Several investigations support that platelet serotonin content and its turnover is reduced in migraineurs between attacks, while the platelet serotonin is released during migraine crises (Anthony, 1986; Ferrari et al., 1989; Goadsby, 1997; Juhasz et al., 2003; Nakano et al., 1993; Sarchielli and Gallai, 2001; Waldenlind et al., 1985). Our recent data support that the platelet 5-HT concentrations are somewhat lower in subjects who developed migraine. The hyposerotonergic status facilitated the pial microvascular dilation in response to intravenous nitroglycerin infusion in an animal model (Srikiatkhachorn et al., 2001). Furthermore, increased NOS activity was observed in a model of serotonin depletion (Tagliaferro et al., 2001). These results suggest that a chronic hyposerotonergic condition is one of the main risk factors that may cause a more intense response to NO in migraineurs when compared to the responses of the controls.

According to our knowledge, only one study has previously investigated the platelet serotonin content during a nitroglycerin-induced headache attack and it failed to show any changes (Dalsgaard-Nielsen et al., 1975). In our studies, we could not detect any significant changes in platelet serotonin content in the subjects with nitroglycerininduced migraine attack. On the other hand, an early and prolonged, highly significant decrease in platelet serotonin content was found in those subjects who did not develop migraine attack during the nitroglycerin test. These data provide evidence for a massive release of serotonin in subjects who did not develop migraine attack. This serotonin release, by acting on $5-\mathrm{HT}_{1 \mathrm{~B} / 1 \mathrm{D}}$ receptors such as tryptans, may cause vasoconstriction and inhibition of evoked trigeminal nucleus firing, release of CGRP and other inflammatory peptides from perivascular nerve terminals, and thus alleviates inflammation and pain (Goadsby and Hoskin, 1998; Johnson et al., 1998; Knyihar-Csillik et al., 1997, 2001). In this regard, changes in 5-HT content do not causally relate to migraine, but secondarily, 5-HT may influence the neurochemical changes during the migraineinduced pain attack.

In conclusion, our results support that lower platelet serotonin concentration and higher basal CGRP concentrations are risk factors that express greater susceptibility to develop both spontaneous and NO-induced migraine attack. Furthermore, plasma CGRP concentration is a dynamically changing trait marker for the migraine-induced pain that suggests a possible causative role of CGRP in migraine. On the other hand, hyposerotonergic conditions may prevent the early induced release of serotonin, which may counteract pain mechanisms by $5-\mathrm{HT}_{1 \mathrm{~B} / 1 \mathrm{D}}$ receptor activation.

\section{Acknowledgements}

The authors would like to thank Sandorne Nagy and Ilona Ozorocyzne Szasz for assistance in blood sampling. The authors are indebted to Sophie Ryde for language corrections. The study was supported by the Hungarian Research Fund Grant T022256/1997, T032398/2000, T-039411, T-043467, TS-040753, NRDP: 1/047/2001, Ministry of Health Research Grant 058/2003 and Postdoctoral PhD Fellowship Program (G.J., 1999-2002) of the Semmelweis University, Ministry of Culture and Education, Hungary. Nemeth J. was supported by the Istvan Szechenyi Fellowship.

\section{References}

Akerman S, Williamson DJ, Kaube H, Goadsby PJ. Nitric oxide synthase inhibitors can antagonize neurogenic and calcitonin gene-related peptide induced dilatation of dural meningeal vessels. Br J Pharmacol 2002;137:62-8

American Psychiatric Association, Diagnostic and statistical manual-IV. Washington, DC: American Psychiatric Press; 1994.

Anthony M. The biochemistry of migraine. In: Clifford Rose F, editor. Handbook of clinical neurology. Headache, vol. 4. Amsterdam: Elsevier; 1986. p. 85-104.

Ashina M, Bendtsen L, Jensen R, Schifter S, Olesen J. Evidence for increased plasma levels of calcitonin gene-related peptide in migraine outside of attacks. Pain 2000;86:133-8.

Ashina M, Bendtsen L, Jensen R, Schifter S, Olesen J. Calcitonin generelated peptide levels during nitric oxide-induced headache in patients with chronic tension-type headache. Eur J Neurol 2001;8:173-8.

Buzzi MG, Moskowitz MA. The trigemino-vascular system and migraine. Pathol Biol (Paris) 1992;40:313-7.

Castellano AE, Micieli G, Bellantonio P, Buzzi MG, Marcheselli S, Pompeo F, Rossi F, Nappi G. Indomethacin increases the effect of isosorbide dinitrate on cerebral hemodynamic in migraine patients: pathogenetic and therapeutic implications. Cephalalgia 1998;18: $622-30$.

Christiansen I, Iversen HK, Olesen J. Headache characteristics during the development of tolerance to nitrates: pathophysiological implications. Cephalalgia 2000;20:437-44.

Dalsgaard-Nielsen T, Bryndum B, Fog-Moeller F, Genefke IK. The effect of percutaneous nitroglycerin upon the concentration of serotonin, 
epinephrine and norepinephrine in venous blood from migrainous subjects during attack-free intervals. Headache 1975;14:231-4.

D’Amico D, Ferraris A, Leone M, Catania A, Carlin A, Grazzi L, Bussone $\mathrm{G}$. Increased plasma nitrites in migraine and cluster headache patients in interictal period: basal hyperactivity of L-arginine-NO pathway? Cephalalgia 2002;22:33-6.

Doods H. Development of CGRP antagonists for the treatment of migraine. Curr Opin Investig Drugs 2001;2:1261-8.

Doods H, Hallermayer G, Wu D, Entzeroth M, Rudolf K, Engel W, Eberlein W. Pharmacological profile of BIBN4096BS, the first selective small molecule CGRP antagonist. Br J Pharmacol 2000;129: 420-3.

Durham PL, Russo AF. Regulation of calcitonin gene-related peptide secretion by a serotonergic antimigraine drugs. J Neurosci 1999;19: 3423-9.

Edvinsson L. A pathophysiological view of primary headaches. Funct Neurol 2000;15(Suppl 3):50-60.

Edvinsson L. Calcitonin gene-related peptide (CGRP) and the pathophysiology of headache: therapeutic implications. CNS Drugs 2001;15: 745-53.

Eltrop CT, Jansen-Olesen I, Hansen AJ. Release of calcitonin gene-related peptide (CGRP) from guinea pig dura mater in vitro is inhibited by sumatriptan but unaffected by nitric oxide. Cephalalgia 2000;20: 838-44.

Fanciulacci M, Alessandri M, Figini M, Gepetti P, Michelacci S. Increase in plasma calcitonin gene-related peptide from the extracerebral circulation during nitroglycerin-induced cluster headache attack. Pain 1995; 60:119-23.

Ferrari MD, Odink J, Tapparelli C, Van Kempen GM, Pennings EJ, Bruyn GW. Serotonin metabolism in migraine. Neurology 1989;39: 1239-42.

Gallai V, Sarchielli P, Floridi A, Franceschini M, Codini M, Glioti G, Trequattrini A, Palumbo R. Vasoactive peptide levels in the plasma of young migraine patients with and without aura assessed both interictally and ictally. Cephalalgia 1995;15:384-90.

Garry MG, Walton LP, Davis MA. Capsaicin-evoked release of immunoreactive calcitonin gene-related peptide from the spinal cord is mediated by nitric oxide but not by cyclic GMP. Brain Res 2000;861: 208-19.

Goadsby PJ. How do the currently used prophylactic agents work in migraine? Cephalalgia 1997;17:85-92.

Goadsby PJ, Edvinsson L. The trigemino-vascular system and migraine: studies characterizing cerebrovascular and neuropeptide changes seen in humans and cats. Ann Neurol 1993;33:48-56.

Goadsby PJ, Edvinsson L. Neuropeptide changes in a case of chronic paroxysmal hemicrania-evidence for trigemino-parasympathetic activation. Cephalalgia 1996;16:448-50.

Goadsby PJ, Hoskin KL. Serotonin inhibits trigeminal nucleus activity evoked by craniovascular stimulation through a $5-\mathrm{HT}_{1 \mathrm{~B} / 1 \mathrm{D}}$ receptor: a central action in migraine? Ann Neurol 1998;43:711-8.

Goadsby PJ, Edvinsson L, Ekman R. Vasoactive peptide release in the extracerebral circulation of humans during migraine headache. Ann Neurol 1990;28:183-7.

Griffiths LR, Nyholt DR, Curtain RP, Goadsby PJ, Brimage PJ. Migraine association and linkage studies of endothelial nitric oxide synthase (NOS3) gene polymorphism. Neurology 1997;49:614-7.

Guicheney P. Human platelet serotonin content: methodological aspects and physiological variations. Meth Find Exptl Clin Pharmacol 1988;10: 253-8.

Headache Classification Committee of the International Headache Society, Classification and diagnostic criteria for headache disorders, cranial neuralgias and facial pain. Cephalalgia 1988;8(Suppl 7):1-96.

Iversen HK. Experimental headache in humans. Cephalalgia 1995;15: $281-7$.

Iversen HK, Olesen J. Headache induced by a nitric oxide donor (nitroglycerin) responds to sumatriptan. A human model for development of migraine drugs. Cephalalgia 1996;16:412-8.
Johnson KW, Phebus LA, Cohen ML. Serotonin in migraine: theories, animal models and emerging therapies. Prog Drug Res 1998;51: 219-44.

Juhasz G, Zsombok T, Laszik A, Jakus R, Faludi G, Sotonyi P, Bagdy G. Despite the general correlation of the serotonin transporter gene regulatory region polymorphism $(5-H T T L P R)$ and platelet serotonin (5-HT) concentration, lower platelet serotonin concentration in migraine patients is independent of the 5-HTTLPR variants. Neurosci Lett 2003;350:56-60.

Kantor S, Graf M, Anhauer ZE, Bagdy G. Rapid desensitization of 5-HT1A receptors in Fawn-Hooded rats after chronic fluoxetine treatment. Eur Neuropharmacol 2001;11:15-24.

Knyihar-Csillik E, Vecsei L. Effect of nitric oxide donor on nitroxergic nerve fibres in the rat dura mater. Neurosci Lett 1999;260:97-100.

Knyihar-Csillik E, Tajti J, Samsam M, Sáry G, Slezak S, Vecsei L. Effect of a serotonin agonist (sumatriptan) on the peptidergic innervation of the rat cerebral dura mater and on the expression of c-fos in the caudal trigeminal nucleus in an experimental migraine model. J Neurosci Res 1997;48:449-64.

Knyihar-Csillik E, Tajti J, Chadaide Z, Csillik B, Vecsei L. Functional immunochemistry of neuropeptides and nitric oxide synthase in the nerve fibres of the supratentorial dura mater in an experimental migraine. Microsc Res Tech 2001;53:193-211.

Lassen LH, Haderslev PA, Jacobsen VB, Iversen HK, Sperling B, Olesen J. CGRP may play a causative role in migraine. Cephalalgia 2002;22: 54-61.

Nakano T, Shimomura T, Takahashi K, Ikawa S. Platelet substance P and 5hydroxytryptamine in migraine and tension-type headache. Headache 1993;33:528-32.

Nemeth J, Gorcs T, Helyes Zs, Oroszi G, Kocsy T, Pinter E, Szolcsanyi J. Development of a new sensitive CGRP radioimmunoassay for neuropharmacological research. Neurobiology 1998;6:473-5.

Nemeth J, Oroszi G, Jakab B, Magyarlaki M, Szilvassy Z, Roth E, Farkas B. ${ }^{125} \mathrm{I}$-labeling and purification of peptide hormones and bovine serum albumin. J Radioanal Nucl Chem 2002;251:129-33.

Ohkuma S, Katsura M. Nitric oxide and peroxynitrite as factors to stimulate neurotransmitter release in the CNS. Prog Neurobiol 2001; 64:97-108.

Olesen J, Iversen HK, Thomsen LL. Nitric oxide supersensitivity: a possible molecular mechanism of migraine pain. NeuroReport 1993;4: 1027-30.

Olesen J, Thomsen LL, Iversen H. Nitric oxide is a key molecule in migraine and other vascular headaches. Trends Pharmacol Sci 1994;15: 149-53.

Pardutz A, Krizbai I, Multon S, Vecsei L, Schoenen J. Systemic nitroglycerin increases nNOS levels in rat trigeminal nucleus caudalis. NeuroReport 2000;11:3071-5.

Pardutz A, Multon S, Malgrange B, Parducz A, Vecsei L, Schoenen J. Effect of systemic nitroglycerin on CGRP and 5-HT afferents to rat caudal spinal trigeminal nucleus and its modulation by estrogen. Eur $\mathbf{J}$ Neurosci 2002;15:1803-9.

Prast H, Philippu A. Nitric oxide as modulator of neuronal function. Prog Neurobiol 2001;64:51-68

Reuter U, Bolay H, Jansen-Olesen I, Chiarugi A, Sanchez del Rio M, Letourneau R, Theoharides TC, Waeber C, Moskowitz MA. Delayed inflammation in rat meninges: implications for migraine pathophysiology. Brain 2001;124:2490-502.

Sarchielli P, Gallai V. Platelets in migraine. J Headache Pain 2001;2: S61-6.

Sarchielli P, Alberti A, Codini M, Floridi A, Gallai V. Nitric oxide metabolites, prostaglandins and trigeminal vasoactive peptides in internal jugular vein blood during spontaneous migraine attacks. Cephalalgia 2000;20:907-18.

Sarchielli P, Alberti A, Floridi A, Gallai V. L-Arginine/nitric oxide pathway in chronic tension-type headache: relation with serotonin content and secretion and glutamate content. J Neurol Sci 2002;198:9-15. 
Srikiatkhachorn A, Anuntasethakul T, Phansuwan-Pujito P, Patumraj S, Kasantikul V. Effect of serotonin depletion on nitric oxide induced cerebrovascular nociceptive response. NeuroReport 2001;12:967-71.

Tagliaferro P, Ramos AJ, López-Costa JJ, López EM, Saavedra JP, Brusco A. Increased nitric oxide synthase activity in a model of serotonin depletion. Brain Res Bull 2001;54:199-205.

Tassorelli C, Joseph AS. Systemic nitroglycerin activates peptidergic and catecholaminergic pathways in rat brain. Peptides 1996;17:443-9.
Tassorelli C, Blandini F, Costa A, Preza E, Nappi G. Nitroglycerin-induced activation of monoaminergic transmission in the rat. Cephalalgia 2002; 22:226-32.

Waldenlind E, Ross SB, Saaf J, Ekbom K, Wetterberg L. Concentration and uptake of 5-hydroxytryptamine in platelets from cluster headache and migraine patents. Cephalalgia 1985;5:45-54.

Zicari A, Giacovazzo M, Martelletti P. Nitric oxide: emerging implications for headache mechanics. J Headache Pain 2001;2:67-72. 